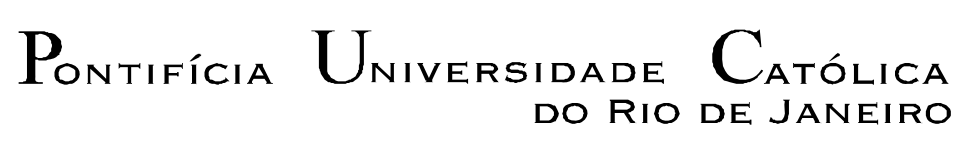
DO RIO DE JANEIRO

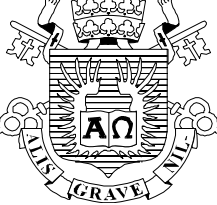

Maria Madalena do Nascimento Sartim

\title{
A Reforma Trabalhista e Sindical do Brasil no contexto de contra-reformas neoliberais:
}

flexibilização de direitos ou (des)ajuste social?

Tese de Doutorado

Tese apresentada ao Programa de Pós-Graduação em Serviço Social do Departamento de Serviço Social do Centro de Ciências Sociais da PUC-Rio como requisito parcial para a obtenção do título de Doutor em Serviço Social.

Orientadora: Profa. Myrtes de Aguiar Macêdo

Rio de Janeiro Junho de 2008 


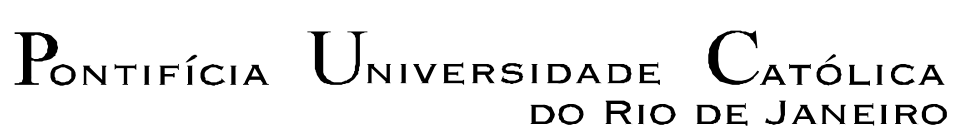

DO RIO DE JANEIRO

Maria Madalena do Nascimento Sartim

\begin{abstract}
A Reforma Trabalhista e Sindical do Brasil no contexto de contra-reformas neoliberais:
\end{abstract}

Flexibilização de direitos ou (des)ajuste social?

Tese apresentada ao Programa de Pós-Graduação em Serviço Social do Departamento de Serviço Social do Centro de Ciências Sociais da PUC-Rio como requisito parcial para a obtenção do título de Doutor em Serviço Social. Aprovada pela Comissão Examinadora abaixo assinada.

Profa. Myrtes de Aguiar Macêdo Orientadora

Departamento de Serviço Social - PUC-Rio

Profa. Franci Gomes Cardoso

Departamento de Políticas Públicas - UFMA

Profa. Sara Granemann Departamento de Serviço Social - UFRJ

Profa. Sueli Bulhões da Silva Departamento de Serviço Social - PUC-Rio

Prof $^{\mathrm{a}}$. Inez Terezinha Stampa Departamento de Serviço Social - PUC-Rio

Prof. Nizar Messari Vice-Decano de Pós-Graduação do Centro de Ciências Sociais - PUC-Rio

Rio de Janeiro, 27 de junho de 2008 
Todos os direitos reservados. É proibida a reprodução total ou parcial sem autorização do autor, do orientador e da universidade.

\section{Maria Madalena do Nascimento Sartim}

Graduou-se em Serviço Social pela UFMA, em 1972, e cursou Mestrado em Serviço Social na PUC-Rio em 1978. Foi membro da Diretoria nacional da ABESS (1985-1987); assessora da Diretoria Executiva do CEDEPSS (1987-1991); membro do Conselho Editorial da Revista Interface do Centro de Ciências Jurídicas e Econômicas da UFES (19962000). Participou de diversos congressos na área de Serviço Social, tendo trabalhos publicados em revistas e anais de eventos na área do Trabalho. É professora associada na UFES e coordenadora do Núcleo de Estudos do Trabalho do departamento de Serviço Social na mesma IFES.

Ficha Catalográfica

Sartim, Maria Madalena do Nascimento

A Reforma Trabalhista e Sindical do Brasil no contexto de contra-reformas neoliberais : flexibilização de direitos ou (des)ajuste social? / Maria Madalena do Nascimento Sartim ; orientadora: Myrtes de Aguiar Macêdo . - 2008.

239f. : il. ; $30 \mathrm{~cm}$

Tese (Doutorado em Serviço Social)-Pontifícia Universidade Católica do Rio de Janeiro, Rio de Janeiro, 2008.

Inclui bibliografia.

1. Serviço social - Teses. 2. Trabalho. 3. Direito do trabalho. 4. Reforma trabalhista e sindical. 5. Flexibilização do trabalho. 6. Desregulamentação do trabalho. I. Macedo, Myrtes de Aguiar. II. Pontifícia Universidade Católica do Rio de Janeiro. Departamento de Serviço Social. III. Título.

CDD: 361 
minha(s) orientadora(s), meus mestres, meus pais (in memory), minha família, meus ex-alunos e todos que me ajudaram em tempos difíceis. 


\section{Agradecimentos}

O processo de construção desta tese constitui-se numa grande e rica experiência marcada não só por descobertas, mas também por dificuldades, essas amenizadas pela presença de grandes companhias. Não posso deixar de registrar os apoios fundamentais à realização deste trabalho que, como um ciclo se fecha, mas, a um só tempo, dá origem a outro.

\section{Quero manifestar meus agradecimentos:}

À minha orientadora, professora Myrtes de Aguiar Macêdo, pela aquiescência ao pedido de continuidade na orientação, pelo convívio sempre enriquecedor e pela sua relevante contribuição para o aprimoramento deste trabalho.

À Professora Franci Gomes Cardoso, que orientou grande parte da tese, entendendo minha idéia quando esta ainda se delineava, e contribuiu com o seu contorno final. Com ela discuti muitos dos conceitos e impasses que abriram caminhos necessários à compreensão meticulosa da temática, cedendo-Ihe parte de sua bagagem intelectual ao ler, comentar, criticar e apoiar sistematicamente a realização da tese. Encorajou-me a seguir uma análise centrada na teoria social, de importância essencial na produção e sustentação de um desejo de pensar diferentemente o Serviço Social, o que procuro fazer neste texto. Foi uma experiência marcada por grande amizade e generosidade, impossível de agradecer.

À CAPES e à PUC-Rio de Janeiro, pelos auxílios concedidos sem os quais a pesquisa não poderia ter sido realizada.

À UFES e ao Departamento de Serviço Social, por terem proporcionado a mim as condições necessárias para a realização do Curso e a elaboração da tese.

Aos professores do Programa de Pós-Graduação da PUC-Rio e do Mestrado em Políticas Sociais da UFES que, graças à realização de suas 
disciplinas, me ofereceram contribuições importantes para 0 encaminhamento de pontos diversos tratados neste estudo. O meu agradecimento pela possibilidade de aquisição de novos conhecimentos, pelo acolhimento e pela rica convivência.

Ao Bill, meu marido, a Rafael, Marco Aurélio e Thaisa, meus filhos, que com incentivo e apoio partilharam comigo a paixão de freqüentar o curso e produzir este trabalho. Em especial, agradeço à Thaisa e ao Marco pelo trabalho de digitação e pela paciência nos momentos em que me foi difícil lidar com o computador. A assistência deles me fazia ver as coisas de forma mais simples e fácil.

Aos meus colegas, incluindo os que já se aposentaram, do Departamento de Serviço Social/UFES, pelo incentivo permanente para o meu afastamento e a realização deste curso, incentivo que impediu que o desânimo se instalasse no meu desejo. Meu eterno agradecimento e amizade de sempre.

Às colegas e amigas da Universidade Federal do Maranhão (UFMA) onde fiz a graduação e iniciei a carreira como professora universitária; em especial à professora, Irmã Maria de Lourdes Nunes Portella, que certa vez me lançou o desafio ao me convidar para ministrar aulas no Departamento de Serviço Social, talvez sem saber que ali se dava o início de nossa longa trajetória profissional. Nestas páginas, espero tê-lo enfrentado mais uma vez, depois de muitos anos. A vocês o meu profundo agradecimento, inclusive pela solidariedade que recebi de cada uma em diferentes situações.

Às minhas colegas de doutorado, Graça e Valéria, pela convivência, pela troca de experiência e reflexões teóricas, pois juntas integramos a segunda turma do curso. Em especial à Graça, pela companhia e convívio maravilhoso, que me deu força e segurança para realizar centenas de viagens ao Rio de Janeiro. A nossa convivência fez relembrar a trajetória que tivemos desde a graduação em Serviço Social na UFMA, o trabalho no CEMA, lá em São Luís, até a função de professora na UFES, tornando a nossa amizade mais forte $e$ perene. A sua generosidade $e$ companheirismo nos tornam amigas para sempre. 
Aos meus ex-alunos do Curso de Serviço Social da UFMA (1974-75), da PUC-Rio (1977) e da UFES (desde 1979), cúmplices de minha história acadêmica, por me oferecerem os mais fortes motivos para o constante aprimoramento intelectual e profissional.

Enfim, agradeço a todos que, de uma forma ou de outra, me estimularam e me ajudaram. 


\section{Resumo}

Sartim, Maria Madalena do Nascimento; Macêdo, Myrtes de Aguiar. A Reforma Trabalhista e Sindical do Brasil no contexto de contra-reformas neoliberais: flexibilização de direitos ou (des)ajuste social? Rio de Janeiro, 2008. 239p. Tese de Doutorado Departamento de Serviço Social, Pontifícia Universidade Católica do Rio de Janeiro.

Esta tese tem como objetivo desvendar a lógica da Reforma Trabalhista e Sindical em curso no Brasil, voltada para a flexibilização dos direitos do Trabalho. Nosso estudo se valeu de uma combinação de estratégias de pesquisa que incluem a definição do marco teórico de referência com base na teoria social como instrumental analítico privilegiado para análise do objeto; uma pesquisa documental para identificar o conjunto de medidas legais e propostas de mudanças na legislação do trabalho no período de 1995 a 2006 e a realização de entrevistas semi-estruturadas a representantes das entidades patronais e das centrais sindicais, para apreender o posicionamento dos trabalhadores e empregadores quanto à Reforma Trabalhista e Sindical. $\mathrm{Na}$ investigação, verificamos que a reforma incide sobre a proteção social do trabalhador no âmbito dos direitos individuais, coletivos e da justiça do trabalho e provoca a desconstrução da regulação social do trabalho com sérias implicações sociais e econômicas: no plano individual, o sistema, além de flexibilizar a jornada, os contratos e rebaixar salários, restringe os direitos e a proteção social dos trabalhadores; no plano coletivo, o modelo proposto é mais um instrumento de conciliação do que de defesa dos trabalhadores contra as empresas e, no plano da Justiça do Trabalho, dificultam-se as ações dos trabalhadores e reduz-se a ação do Estado. A análise revela que as modificações na legislação implicam perdas de

direitos e retrocesso das conquistas históricas dos trabalhadores. $\mathrm{O}$ corolário é a legitimação das formas de precarização do emprego, o que reforça a fuga de direitos e a troca do trabalho protegido pelo trabalho desprotegido.

\section{Palavras-chave}

Trabalho; Direito do Trabalho; Reforma Trabalhista e Sindical; Flexibilização do Trabalho; Desregulamentação do Trabalho. 


\section{Abstract}

Sartim, Maria Madalena do Nascimento; Macêdo, Myrtes de Aguiar (Advisor). The Reform and Labor Unions of Brazil in the context of neo-liberal counter-reforms: flexibilization of the rights or (un)social adjustment? Rio de Janeiro, 2008. 239p. Tese de Doutorado - Departamento de Serviço Social, Pontifícia Universidade Católica do Rio de Janeiro.

This paper aims to find out the logic of the labor and syndicate reformation going on in Brazil, focusing on the flexibilization of the labor's rights. Our research combined strategies which includes the definition of the theoretical mark of reference based on the social theory as an analytic instrument special for the analysis of the object; a documental research to identify the set of legal acts and proposals to change the labor's legislation in the period from 1995 to 2006; and the realization of interviews halfstructured to representatives of the employers' entities and to the head syndicates, in order to apprehend where both employers and employees stand regarding the labor and syndicate reformation. Within the investigation we verified that the reformation goes against the social protection of the worker in terms of individual and collective rights and in terms of the labor's justice, and provokes the deconstruction of the social regulation of labor, causing serious economical and social implications: In the individual field, the system, besides making working hours and the contracts flexible and diminishing the wages, restricts the workers' social rights and protection; In the collective field, the model proposed is more likely a way of reconciliation than a way of defense for the workers against the companies and, in the Labor's Justice field, it makes workers' actions difficult and diminishes the State's action. The analysis reveals that the changes in the legislation imply losses of rights and the retreat of the workers' historical conquests. The corollary is the legitimacy of the ways that turn employment precarious, which reinforce the evasion of rights and the shifting from protected labor to non-protected labor.

\section{Keywords}

Labor; Labor's rights; Labor and syndicate reformation; Flexibilization of the labor; Desregulamentation of the labor. 


\section{Sumário}

1 Introdução 14

1.1 Apresentação do Problema

1.2 A Reforma Trabalhista e Sindical: Contextualização e Debate Teórico 23

1.3 Estrutura e Procedimento Metodológico 33

2 Lugar do Trabalho no Processo de Valorização do Capital na Contemporaneidade: Contexto Histórico

2.1 A cebtralidade do Trabalho em Marx.

2.2 O Debate sobre o Fim da Centralidade do Trabalho 58

2.3 A Configuração do Trabalho no Capitalismo Avançado:

da Crise do Fordismo aos Desafios Atuais .................................... 63

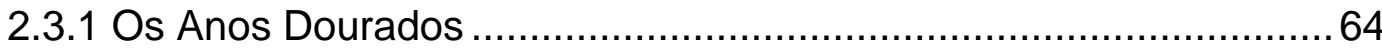

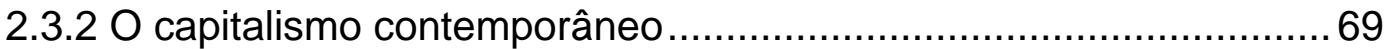

3 O Direito do Trabalho no Brasil: da Regulação à Desregulação 84

3.1 A Legislação do Trabalho como Espaço de Reconhecimento e Conflito 85

3.2 A Regulação Social do Trabalho no Brasil .................................. 91

3.3 O Entendimento da Flexibilização/Desregulamentação ............. 101

3.4 Os Direitos Trabalhistas no Contexto da Crise Estrutural: Retrocesso na sua Concepção

3.5 Antecedentes históricos da contra-reforma trabalhista e sindical

4 A Reforma Trabalhista e Sindical do Brasil no Contexto de Contra-Reformas Neoliberais.

4.1 Rediscutindo o Conceito de "Reforma do Estado"

4.2 Crise do Reformismo e a "Nova" Relação

Estado/Sociedade Civil

4.3 A Reforma do Estado brasileiro pós-94

4.4 A (Contra-) Reforma Trabalhista e Sindical do Governo

FHC 
4.4.1 Flexibilização dos Contratos (Atípicos) de Trabalho 147

4.4.2 Flexibilização da Jornada de Trabalho ................................... 164

4.4.3 Flexibilização da Remuneração ......................................... 170

4.4.4 As Formas de Solução de Conflito (Justiça do Trabalho) .......173

4.4.5 Da Prevalência do Negociado sobre o Legislado em

Acordos Coletivos

5 A (Contra-) Reforma Trabalhista e Sindical do Governo Lula .......178

5.1 A Posição do FNT sobre a Representação dos Trabalhadores . 182

5.2 Análise da Posição do FNT sobre a Negociação Coletiva......... 186

5.3 As Alterações da Legislação Trabalhista no Governo Lula ....... 187

5.4 A Concepção dos Trabalhadores e Empresários sobre

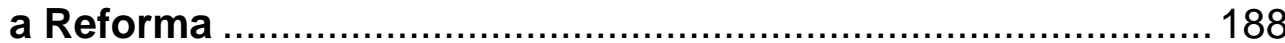

5.4.1 O Posicionamento da CUT ............................................... 190

5.4.2 O Posicionamento da FS ..................................................... 194

5.4 .3 O Posicionamento da CNI .............................................. 198

5.4.4 O Posicionamento da CNC .................................................. 200

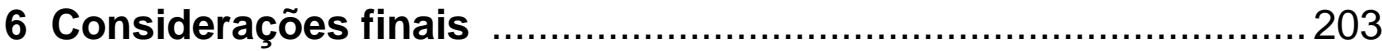

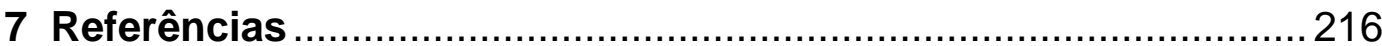




\section{Listas de Siglas}

CAPES Fundação Coordenação de Aperfeiçoamento de Pessoal de Ensino Superior

CDES Conselho de Desenvolvimento Econômico e Social

CF Constituição Federal

CGT Central Geral dos Trabalhadores

CGTB Confederação Geral dos Trabalhadores do Brasil

CLT Consolidação das Leis do Trabalho

CNA Confederação Nacional da Agricultura

CNC Confederação Nacional do Comércio

CNF Confederação Nacional das Instituições Financeiras

CNI Confederação Nacional da Indústria

CNTC Confederação Nacional dos Trabalhadores no Comércio

CNTI Confederação Nacional dos Trabalhadores na Indústria

CONCLAT Coordenação das Classes Trabalhadoras

CUT Central Única dos Trabalhadores

DIAP Divisão Intersindical de Assessoria Parlamentar

DIEESE Departamento Intersindical de Estatística e Estudo SócioEconômico

EUA Estados Unidos da América

FAT Fundo de Amparo ao Trabalhador

FEBRABAN Federação Brasileira de Bancos

FENABAN Federação Nacional dos Bancos

FGTS Fundo de Garantia por Tempo de Serviço

FHC Fernando Henrique Cardoso 
FIESP Federação das Indústrias do Estado de São Paulo

FMI Fundo Monetário Internacional

FNT Fórum Nacional do Trabalho

FS Força Sindical

IBGE Instituto Brasileiro de Geografia e Estatística

IEDI Instituto de Estudos para o Desenvolvimento Industrial

MP Medida Provisória

MPT Ministério Público do Trabalho

MTE Ministério do Trabalho e Emprego

OCDE Organização para a Cooperação e Desenvolvimento

Econômico

OIT

Organização Internacional do Trabalho

OMC Organização Mundial do Comércio

PAE Programa de Ajuste Estrutural

PEA População Economicamente Ativa

PEC Projeto de Emenda Constitucional

PIB $\quad$ Produto Interno Bruto

PL Projeto de Lei

PLR Participação nos Lucros e Resultados

PNAD Pesquisa Nacional de Amostra de Domicílios

PUC-Rio Pontifícia Universidade Católica do Rio de Janeiro

SENAES Secretaria Nacional de Economia Solidária

SENAI Serviço Nacional de Aprendizagem da Indústria

SESC Serviço Social do Comércio

SESI Serviço Social da Indústria

UFES Universidade Federal do Espírito Santo

UFMA Universidade Federal do Maranhão

UFRJ Universidade Federal do Rio de Janeiro 